\title{
Evaluating Unsaturated Flow of Heap Leach Materials in Large Diameter Column Tests
}

\author{
V. Galla Newmont Mining Corporation, USA \\ D. van Zyl University of British Columbia, Norman B. Keevil Institute of Mining Engineering, Canada
}

S. Morrow Applied Soil Water Technologies, USA

\begin{abstract}
Two large columns (1.3 $\mathrm{m}$ diameter by $2 \mathrm{~m}$ tall) were filled with crushed and run-of-mine heap leach ore respectively. These columns were instrumented to measure water content and matric suction; the instruments were sourced from two different manufacturers. Water was applied on the top of each column at a range of calibrated flow rates and outflows were measured using tipping bucket rain gauges. A data logger collected all the instrument data from where it was transferred to a computer. This paper describes the grain size, saturated hydraulic conductivity and unsaturated flow parameters of the heap leach materials as well as the column experimental set-up and results. The observed results are discussed as they relate to the flux application rate, drain down and relative values of water content and matric suction. The results of this study provide important insights in the unsaturated flow behaviour in heap leach facilities.
\end{abstract}

\section{Introduction}

Heap leaching practice is a maturing technology in the mining industry, its importance and advantages has led to widespread application in the gold/silver and copper industries because of low capital and operating cost, as compared to milling and other extraction processes (van Zyl et al., 1988). Column testing is typically used during metallurgical evaluations where column sizes may vary in diameter from $10 \mathrm{~cm}$ to $1 \mathrm{~m}$. However, similar tests are not done to evaluate unsaturated flow conditions.

The research described in this paper involves measuring water content, matric suction and discharge under different unsaturated flow conditions (low to high flux) in two heap leach materials (fine and coarse) (Galla, 2007). Two large cylindrical columns, $1.3 \mathrm{~m}$ diameter and $2 \mathrm{~m}$ tall, are used in this research. The bottom parts of the columns are cone shaped to enhance collection of the outflow. The cone shaped bottoms are filled with drain rock and heap leach rock fills the cylindrical part. Four instrument clusters are about equally spaced in the columns.

\section{Previous investigations}

Although there are many publications about theoretical aspects and laboratory column tests of unsaturated flow in soils (e.g. Fredlund and Rahardjo, 1993), only a few studies have been done with coarse materials in columns. This section will briefly review these studies and their outcomes.

Cathles and Murr (1980) and Murr et al. (1981) report on column testing of copper heap leach ore in $3.1 \mathrm{~m}$ diameter by $10.8 \mathrm{~m}$ tall columns. They investigated the effects of particle size distribution, rock dissolution during leaching, flow channel size and location and column material permeability and leaching efficiency. These studies were focused on the economics of heap leaching of copper ore.

Dixon (1992) and Dixon and Hendrix (1993) propose a non-steady state model for the leaching of several mineral species within the ore with different variable order rate expressions. Dimensionless model equations were developed and used to identify important design and scale up factors. A new flow and transport model similar to dual-porosity model by Parker and van Genuchten (1984) was proposed, but it did not show any improvements over the advection dispersion equation model.

Decker (1996) evaluated rinsing cycles on heap leach material using tracers on small diameter samples and large diameter samples at flux rates of 7.3 and $12.2 \mathrm{~L} / \mathrm{hr} / \mathrm{m}^{2}$ respectively. It was concluded that 
heterogeneous velocity fields rather than a uniform velocity field govern the hydraulic and solute transport process in a heap leach pile.

Decker and Tyler (1999) developed an understanding of hydraulic and solute transport characteristics in precious metal heap leach operations by analysing breakthrough (the amount of time required for the solute to appear in the outflow) data from the U.S. Bureau of Mines (USBM) laboratory column tracer tests (Dix et al., 1992). Tracer experiments with sodium bromide were conducted using spent ore from a large scale heap in the Carlin trend. A $20.3 \mathrm{~cm}$ diameter by $6 \mathrm{~m}$ tall column incorporating time domain reflectometry (TDR) to investigate rinsing characteristics of spent heap leach material. The dual porosity model and advection dispersion modelling were compared with the data from experiments. The dual porosity model provided improved estimates of the hydraulic and solute transport behaviour of a heap (Decker and Tyler, 1999). The results also suggested that preferential pathways exist that allow the applied fluid to rapidly migrate without contacting the heap material.

Newman et al. (1998) performed a column study followed by numerical modelling on an unsaturated waste rock pile consisting of steeply dipping layers of fine and coarse material located adjacent to one another. The results of the column study and numerical modelling programme indicate that in unsaturated environments water flows preferentially through fine grained rather than coarse-grained material, and this preferential flow is a result of changes in hydraulic conductivity of two materials with increasing suctions. The study illustrated the complexity of unsaturated flow hydrogeology in layered materials such as waste rock and heap leach piles.

Nichol et al. (2000), reports lysimeter studies. These studies investigated unsaturated flow through a waste rock pile, $8 \times 8 \times 5 \mathrm{~m}$ high and $1 \mathrm{~m}$ diameter $\times 2 \mathrm{~m}$ tall laboratory column experiments. The results suggested that water flows slowly through a finer grained matrix, but may also be channeled to spatially distinct pathways. Nichol et al. (2000) report water content and matric suction measurements, and found that taking measurements in a large waste rock pile using instruments poorly represented the advance of the wetting front through the pile.

Webb (2003) investigated the percolation collection efficiency of lysimeters, degree of spatial variation of flow and its principal causes and also the applicability of Hydrus-2D in modelling fluid flow in highly heterogeneous materials. This work focused on the Gold Acres leach pad at the Cortez mine; materials for one of the columns in the present research were obtained from the same location. Webb found that the principal cause for low percolation collection efficiency was the low hydraulic conductivity of lysimeter fill material, which caused the collected solution to spill over the sides before reaching the drain, and flow diversion around lysimeter was due to the heterogeneity in the material. The spatial variability of flow in the heap material was due to heterogeneity of hydraulic parameters instead of variability of the application rate (Webb, 2003; Webb et al., 2008).

Heap leach piles are similar in geometry to waste rock facilities; but may not be similar in particle size distribution and structure (Kampf et al., 2002). Fluid flow is dominated by preferential flow in heap leach ore (caused by ore conveyance, stacking, sorting and dumping) (Orr, 2002), and may not follow common fluid flow laws (Darcy's law and Richards equation) because of voids that result from construction methods (Kampf et al., 2002).

\section{Heap leach materials and characterisation}

Two heap leach materials, crushed (Rawhide), and run-of mine (Cortez) were used in the present research. Laboratory testing of the samples were done by two commercial laboratories: Applied Soil Water Technologies, LLC, Reno (ASWT), and Geosystems Analysis Inc. (GSA), Tucson. Figures 1 and 2 show the particle size distributions of the Rawhide and Cortez material respectively obtained by ASWT and GSA.

Saturated hydraulic conductivities for Rawhide and Cortez materials were obtained by constant head tests using Marriot bottles; the tests were done on $25.4 \mathrm{~cm}$ and $20.32 \mathrm{~cm}$ diameter samples at the University of Nevada, Reno (UNR) and ASWT respectively. Table 1 shows the results of the saturated hydraulic conductivity test results obtained from UNR and ASWT.

Testing for soil water characteristic curves (SWCC) was done at Applied Soil Water Technologies Inc. (ASWT) on scalped samples, $6.15 \mathrm{~cm}$ diameter and $2.54 \mathrm{~cm}$ thick using a Tempe cell. The particle sizes 
considered by ASWT for the small sample tests were passing No. 4 sieve and No. 10 sieve. SWCC testing was done at Geosystems Analysis, Inc. (GSA) using a $30.48 \mathrm{~cm}$ diameter and $30.48 \mathrm{~cm}$ thick samples. Testing consisted of a combination of hanging water column and pressure plate extraction methods in accordance with ASTM D 6836 methods A and B. The samples used by GSA in the large sample had particle sizes passing $37.5 \mathrm{~mm}$. Figures 3 and 4 show the SWCC of Rawhide and Cortez materials, respectively, done by ASWT (scalped sample) and GSA (large sample).

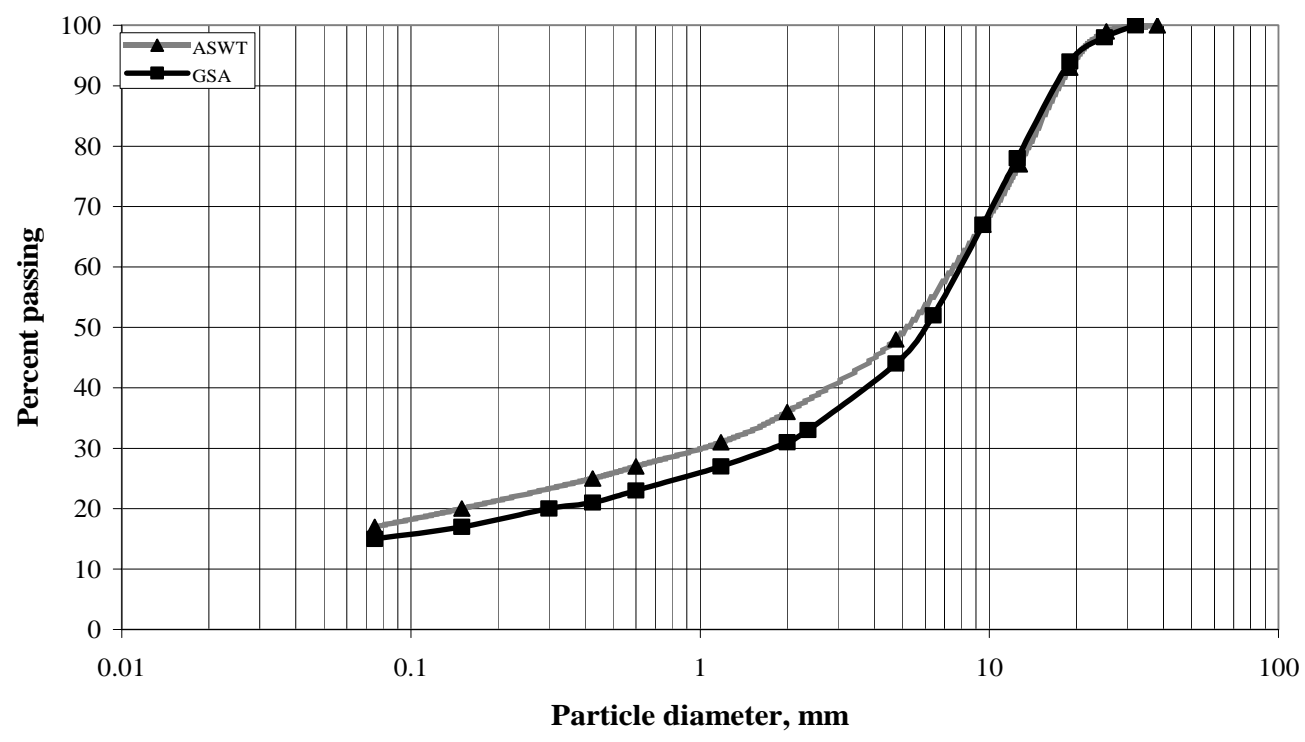

Figure 1 Particle size distribution of Rawhide heap leach material

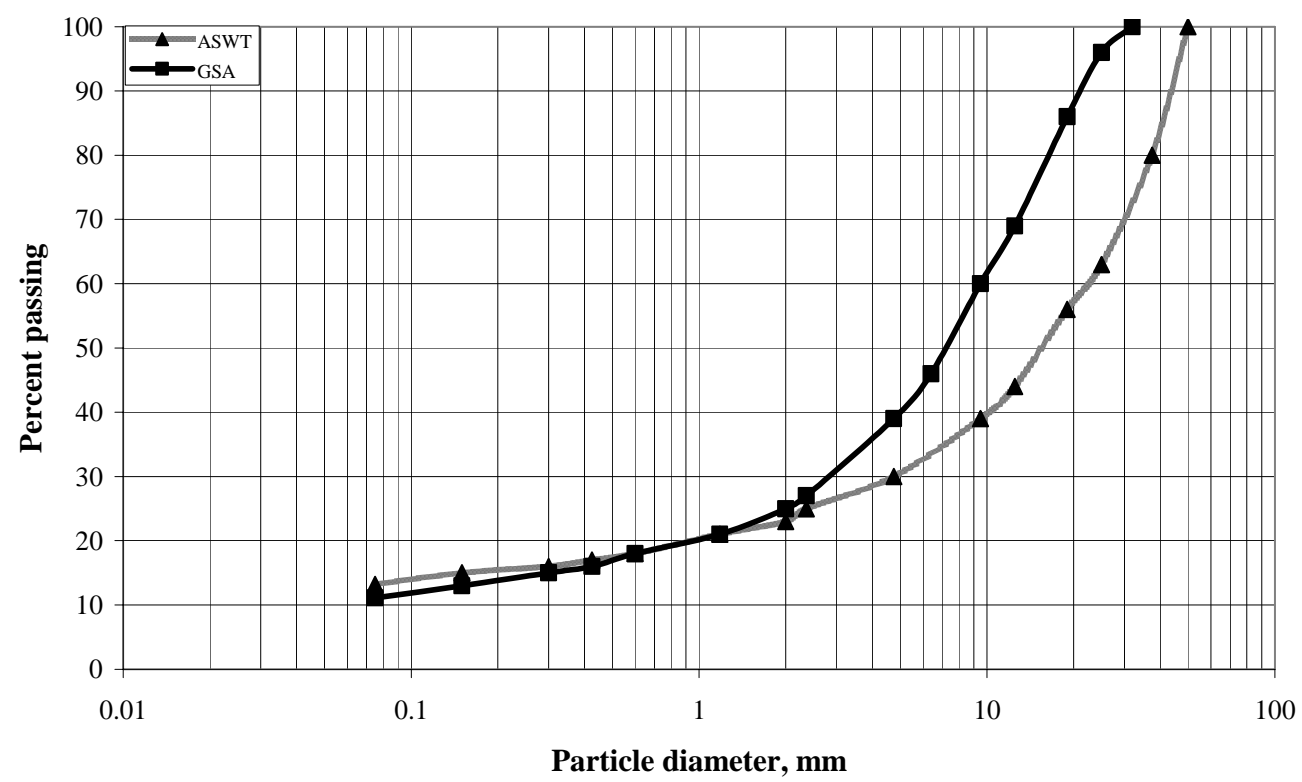

Figure 2 Particle size distribution of Cortez heap leach material 
Table 1 Saturated hydraulic conductivity of heap leach materials in cm/sec.

\begin{tabular}{|c|c|c|c|}
\hline $\begin{array}{c}\text { Constant head } \\
(\mathbf{c m})\end{array}$ & $\begin{array}{c}\text { Rawhide, 20.3 cm } \\
\text { dia. sample (ASWT) }\end{array}$ & $\begin{array}{c}\text { Rawhide, 25.4 cm } \\
\text { dia. sample (UNR) }\end{array}$ & $\begin{array}{c}\text { Cortez, 20.3 cm } \\
\text { dia. sample (ASWT) }\end{array}$ \\
\hline 2.54 & $3.1 \times 10^{-2}$ & $2.1 \times 10^{-1}$ & $5.4 \times 10^{-1}$ \\
\hline 7.62 & $1.9 \times 10^{-2}$ & $1.4 \times 10^{-1}$ & $5.1 \times 10^{-1}$ \\
\hline 15.24 & $1.0 \times 10^{-2}$ & $1.4 \times 10^{-1}$ & $4.7 \times 10^{-1}$ \\
\hline 30.48 & $7.0 \times 10^{-3}$ & $1.1 \times 10^{-1}$ & $4.0 \times 10^{-1}$ \\
\hline
\end{tabular}

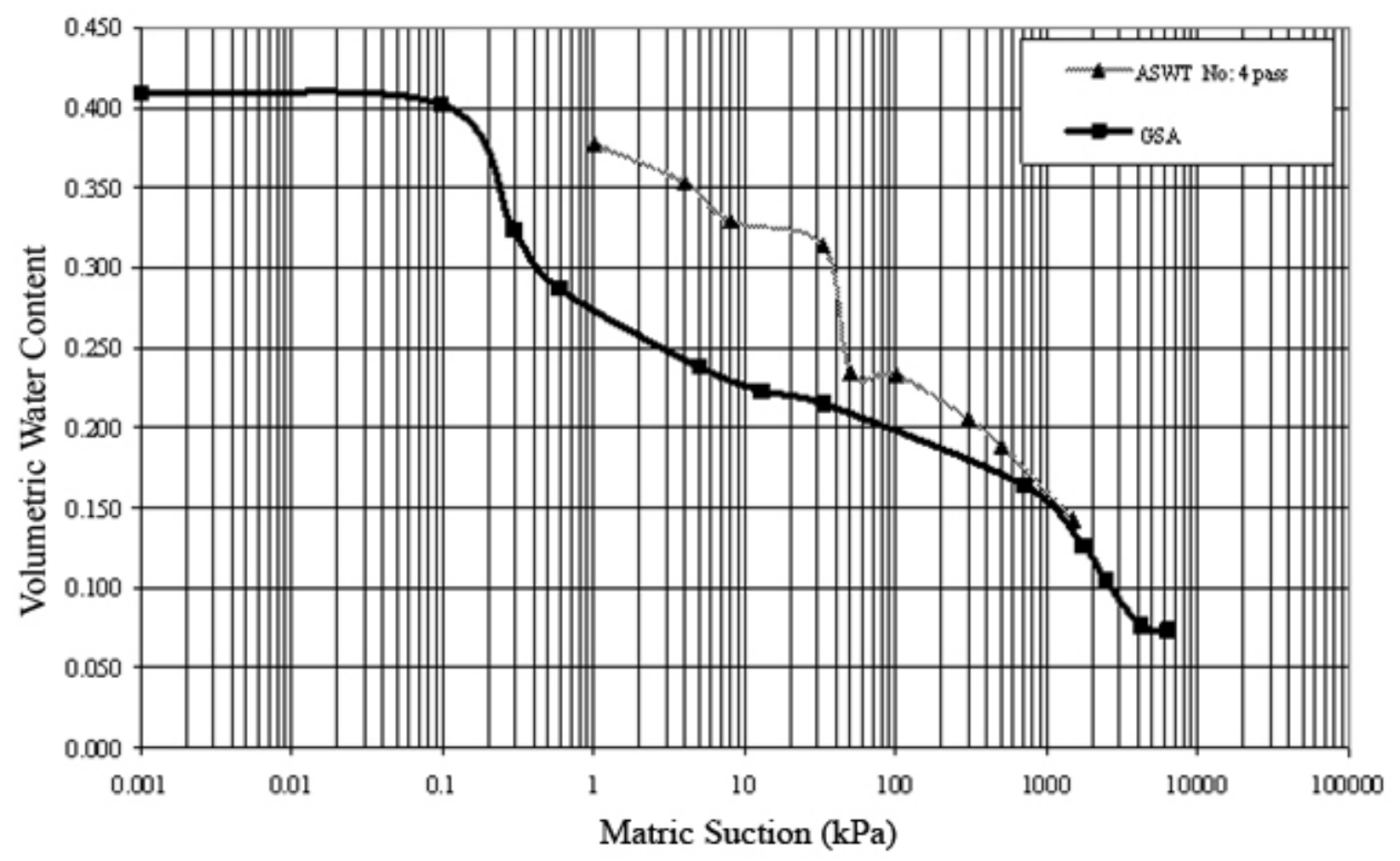

Figure 3 Soil water characteristics curves for Rawhide material

\section{Experimental details}

Two large cylindrical steel columns $1.3 \mathrm{~m}$ in diameter and $2 \mathrm{~m}$ in height were used in the present research. The bottom part of the each column was cone shaped to enhance outflow collection. Each column had four instrumentation ports at four different depths. Figure 5 shows a schematic of the column and instrument layout.

Table 2 presents a summary of the instruments used in each of the clusters in the experimental design. All instruments were calibrated in containers filled with heap leach materials. Realistic calibrations were obtained for the instruments supplied by Decagon, while difficulties were experienced for the other instruments. These difficulties were associated with procedures used to calibrate the heat dissipation sensors and the multiplexer used in the data logger for the TDR sensors. Detailed evaluations late in the experimental program helped to identify the problems, however it was too late to correct these. The data from these instruments were therefore not useful. A neutron probe was not used in the research because of licensing issues. 


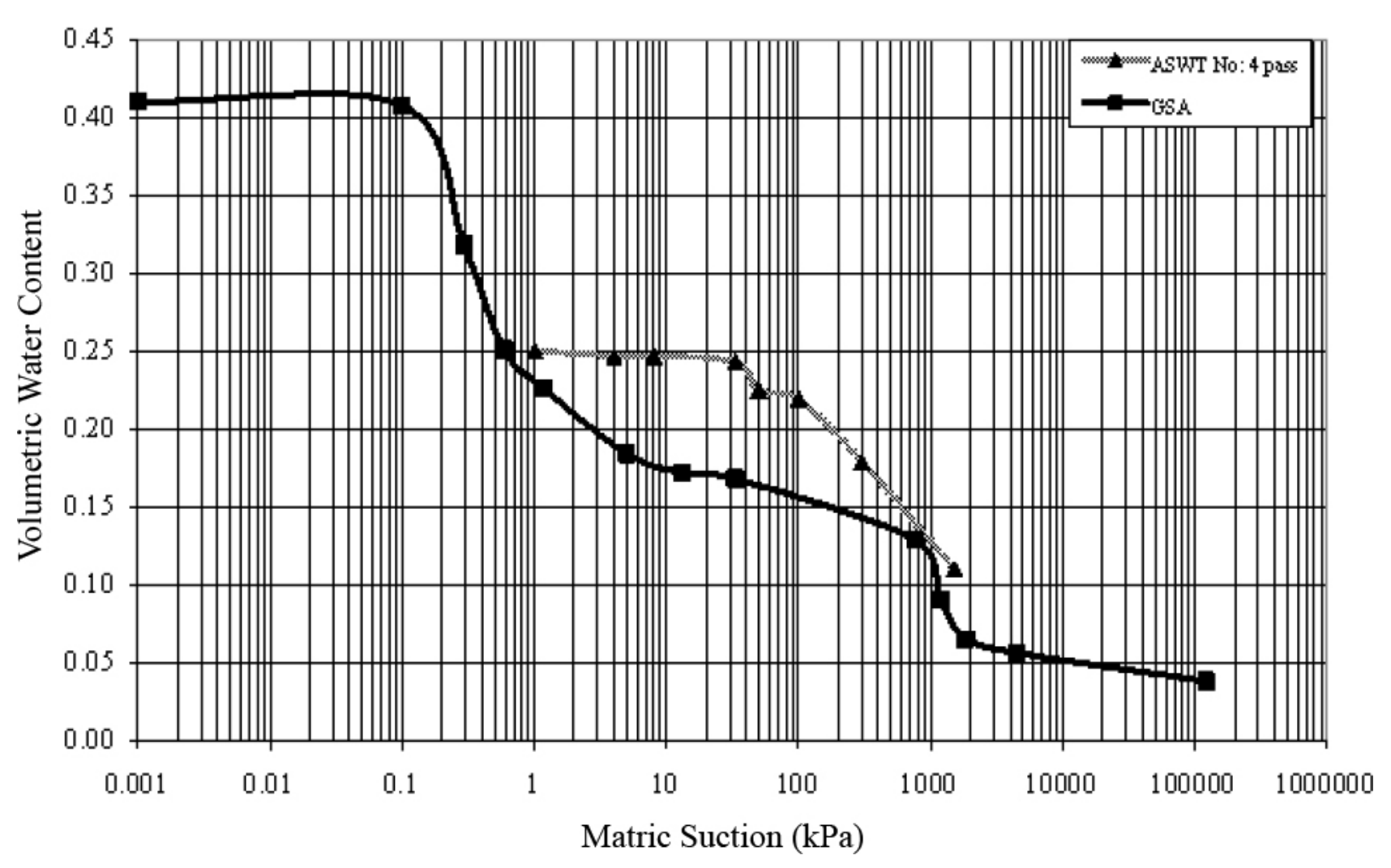

Figure 4 Soil water characteristics curves for Cortez material

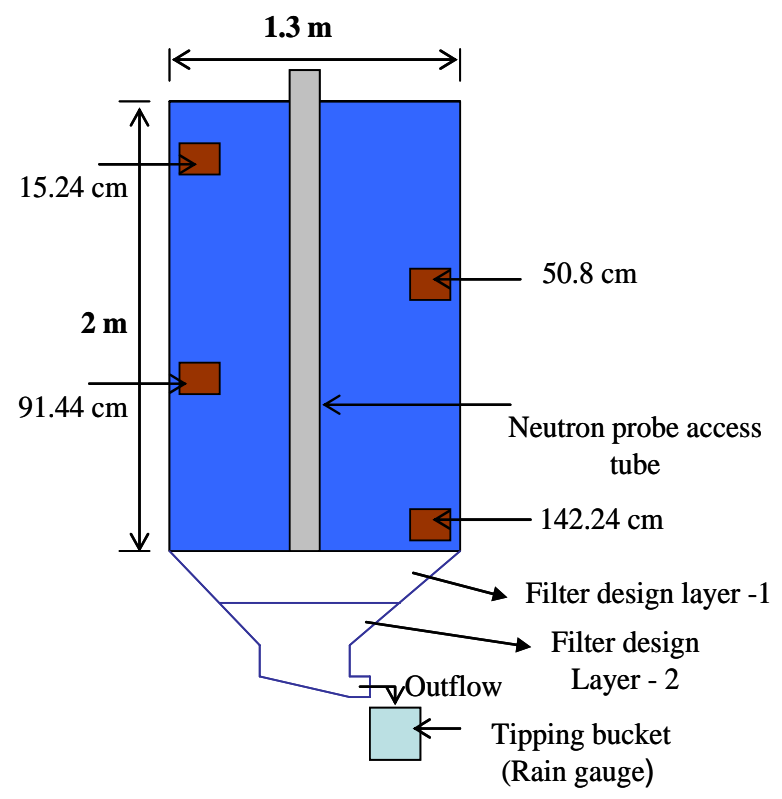

\begin{tabular}{|c|c|}
\hline Filter Design & Description \\
\hline Filter design - 1 & $\begin{array}{l}\text { Mixture of } 19 \mathrm{~mm} \\
\text { gravel and concrete } \\
\text { sand }(20 \%)\end{array}$ \\
\hline Filter design - 2 & $\begin{array}{l}\text { Mixture of } 38 \mathrm{~mm} \text { and } \\
19 \mathrm{~mm} \text { gravel }\end{array}$ \\
\hline
\end{tabular}

Figure 5 Column and instrumentation set-up 
Table 2 Instruments used in the research

\begin{tabular}{|c|c|c|c|}
\hline Instrument & Supplier & Parameter Measured & Principle of Operation \\
\hline EC-20 probe & Decagon Devices Inc & Volumetric water content & Capacitance based \\
\hline Time domain reflectometry & Campbell Scientific Inc & Volumetric water content & Reflections (wave forms) \\
\hline Echo matric probe & Decagon Devices Inc & Matric suction & Capacitance based \\
\hline Heat dissipation sensor & Campbell Scientific Inc & Matric suction & Thermal conductivity \\
\hline
\end{tabular}

\subsection{Setting up the columns}

Rawhide material was placed in Column A; the material was shipped in 20 L buckets, in three increments, approximately 1 tonne per increment. The column containing Cortez material also required about three tonnes to fill leaving the same free space at the top of the column as in the Rawhide column. The weight of each $20 \mathrm{~L}$ bucket added to the column was recorded to calculate the average in place density of the material in the column. The average bulk densities for the columns with Rawhide material was $1650 \mathrm{~kg} / \mathrm{m}^{3}$ and $1730 \mathrm{~kg} / \mathrm{m}^{3}$ for Cortez material. After applying the flux to the columns the material settled and the final average densities of the material (assuming the same weight of materials as the initial) were $1712 \mathrm{~kg} / \mathrm{m}^{3}$ and $1858 \mathrm{~kg} / \mathrm{m}^{3}$ respectively for the Rawhide and Cortez columns.

Bentonite was used as a sealant and was placed in strips of $25 \mathrm{~mm}$ thick and $37 \mathrm{~mm}$ height at two different depths (50.8 cm and $91.44 \mathrm{~cm}$ levels from the bottom) along the circumference of the column to avoid preferential flow along the sides of the column. The cables from the instrument clusters were taken through small openings in plexiglas covers that were used to cover the instrument ports. The remaining openings were sealed with bentonite from the inside and silica gel from the outside to avoid leakage. Instrument locations are shown on Figure 5 and are based on the distance from the top of the original material surface.

The Rawhide material had very low water content when placed in the column as it was air dried before delivery to the laboratory. Part of the Cortez material was damp upon placement.

\subsection{Flux application}

Flux application was done using a peristaltic pump with two pump heads, one for the column containing Rawhide material, and another for the column containing Cortez material. The outflow from the columns was collected using tipping bucket rain gauges. Table 3 details the flux application rate and periods of flux application and draindown.

The flow was distributed on top of the columns using a concentric ring arrangement having three rings with Rainbird drippers spaced $6 \mathrm{~cm}$ apart. The three rings had the following number of drippers and approximate diameter: outer ring 54 and $1 \mathrm{~m}$; second ring 34 and $0.8 \mathrm{~m}$; and inner ring 21 and $0.5 \mathrm{~m}$.

\subsection{Data acquisition}

A data logger model CR-23X from Campbell Scientific was used for data acquisition. The collected data were transferred to a computer on a regular basis for data analysis. The data for the Rawhide column were collected under no-flow application for a month and at targeted flow applications for more than a year (May 2006 to July 2007).

The monitoring results were recorded at regular intervals to evaluate variability in instrument readings, and breakthrough time at targeted flow rates. The data collection programme was updated regularly to facilitate the changes in the flow application and user specified time intervals for data collection. 
Table 3 Flux application details

\begin{tabular}{|c|c|c|c|c|}
\hline \multirow{4}{*}{ Material } & $\begin{array}{c}\text { Targeted Flux Rate } \\
\mathbf{L} / \mathbf{h r} / \mathbf{m}^{2} *\end{array}$ & Month of Application & Application / Days & Draindown / Days \\
\hline \multirow{4}{*}{ Rawhide } & Dry & May-06 & - & - \\
\cline { 2 - 5 } & 1.7 & Jul-06 & $0-33$ & $33-81$ \\
\cline { 2 - 5 } & 2.4 & Oct-06 & $81-103$ & $103-134$ \\
\cline { 2 - 5 } & 7.3 & Dec-06 & $134-145$ & $145-200$ \\
\hline \multirow{3}{*}{ Cortez } & 12.2 & Apr-07 & $200-204$ & $204-209$ \\
\cline { 2 - 5 } & 2.4 & Oct-06 & $0-22$ & $22-54$ \\
\cline { 2 - 5 } & 7.3 & Dec-06 & $54-64$ & $64-118$ \\
\hline
\end{tabular}

* Note the conversion factor for flux rate is $1 \mathrm{gpm} / \mathrm{ft}^{2}=2,444.75 \mathrm{~L} / \mathrm{hr} / \mathrm{m}^{2}$

\section{$5 \quad$ Selected test results}

Figure 6 shows the water content profiles for the Rawhide column at targeted flow rates beginning from low $\left(1.7 \mathrm{~L} / \mathrm{hr} / \mathrm{m}^{2}\right)$ rate and ending at a high $\left(12.2 \mathrm{~L} / \mathrm{hr} / \mathrm{m}^{2}\right)$ flow rate. The figure shows varied and high water content during initial low flux application rate $\left(1.7 \mathrm{~L} / \mathrm{hr} / \mathrm{m}^{2}\right)$ at all four depths of the column. A change in the water contents over the first 35 days of the test at different depths can be observed. The water content at $50.8 \mathrm{~cm}$ depth increased after 20 days of the flux application. Slight deviations in the water content profiles were observed at 15.24, 50.8, $91.44 \mathrm{~cm}$ depths before reaching steady state from about 1 to 5 days. Only small changes were observed in the water content at $142.24 \mathrm{~cm}$ depth, suggesting potential influence from the filter material in the conical part of the column.

Figure 7 shows the water content profile over time and at different application rates for the Cortez column at four different depths $(15.24,50.8,91.44$, and $142.24 \mathrm{~cm})$. The EC-20 probes recorded consistent data throughout the experiment. The water contents at $50.8 \mathrm{~cm}$ depth showed higher values for the initial application rate for the higher application rates. It also recorded higher values throughout the time history. The water contents at the other three depths $(15.24,91.44$, and $142.24 \mathrm{~cm})$ varied from $11 \%$ to $21 \%$. This distribution of water contents may be due to preferential flow in the macropores of the coarse Cortez run-ofmine material or due to calibration of the instruments. During the final flow application $\left(12.2 \mathrm{~L} / \mathrm{hr} / \mathrm{m}^{2}\right)$ the water content at the top two depths, i.e. $15.24 \mathrm{~cm}(13 \%$ to $18 \%)$ and $50.8 \mathrm{~cm}$ (23\% to 28\%) increased more than the water content at lower depths of $91.44 \mathrm{~cm}(16 \%$ to $17.5 \%)$ and $142.24 \mathrm{~cm}$ (18\% to 20\%). This may also be the result of preferential flow paths in the column.

Figure 8 shows the matric suction profiles for the Rawhide column measured using Echo matric probes. The profile shows suction measurements at three depths $(15.24,50.8$, and $91.44 \mathrm{~cm}$. The matric suction readings in the Rawhide column were erratic during the initial flow condition $\left(1.7 \mathrm{~L} / \mathrm{hr} / \mathrm{m}^{2}\right)$ due to the dry condition of the rock. However, when the flow was increased to the next flux level $\left(2.4 \mathrm{~L} / \mathrm{hr} / \mathrm{m}^{2}\right)$ the matric suction profile appeared uniform, with increase in suction during draindown and decrease during flux application.

The matric suction profiles in the Cortez column (Figure 9) did not show much change in the suction values. The probes, which were placed at depths $142.24 \mathrm{~cm}$ and $50.8 \mathrm{~cm}$, recorded a constant suction measurement with little variations during different flow rates. 


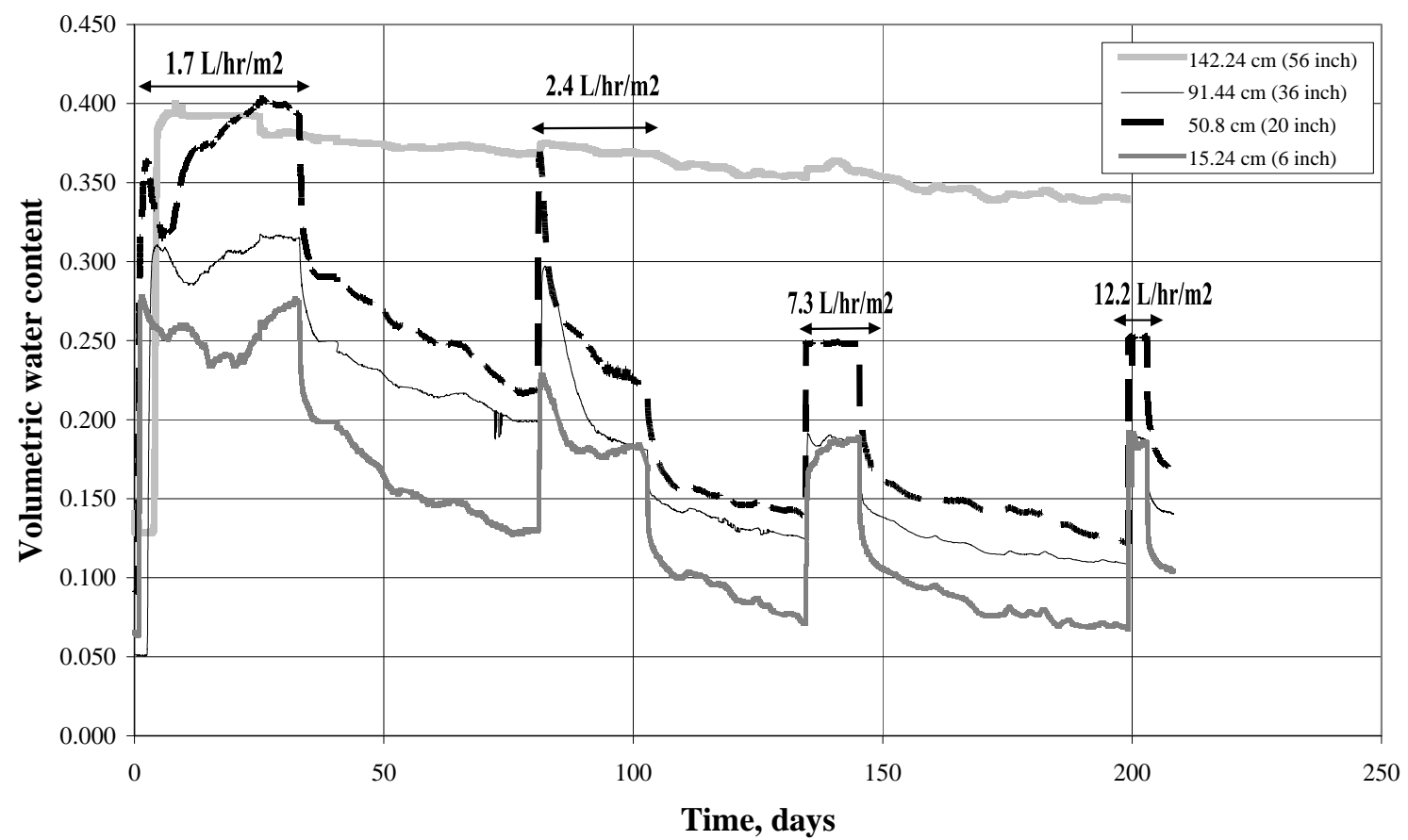

Figure 6 Volumetric water content observed with EC-20 probes in Rawhide column

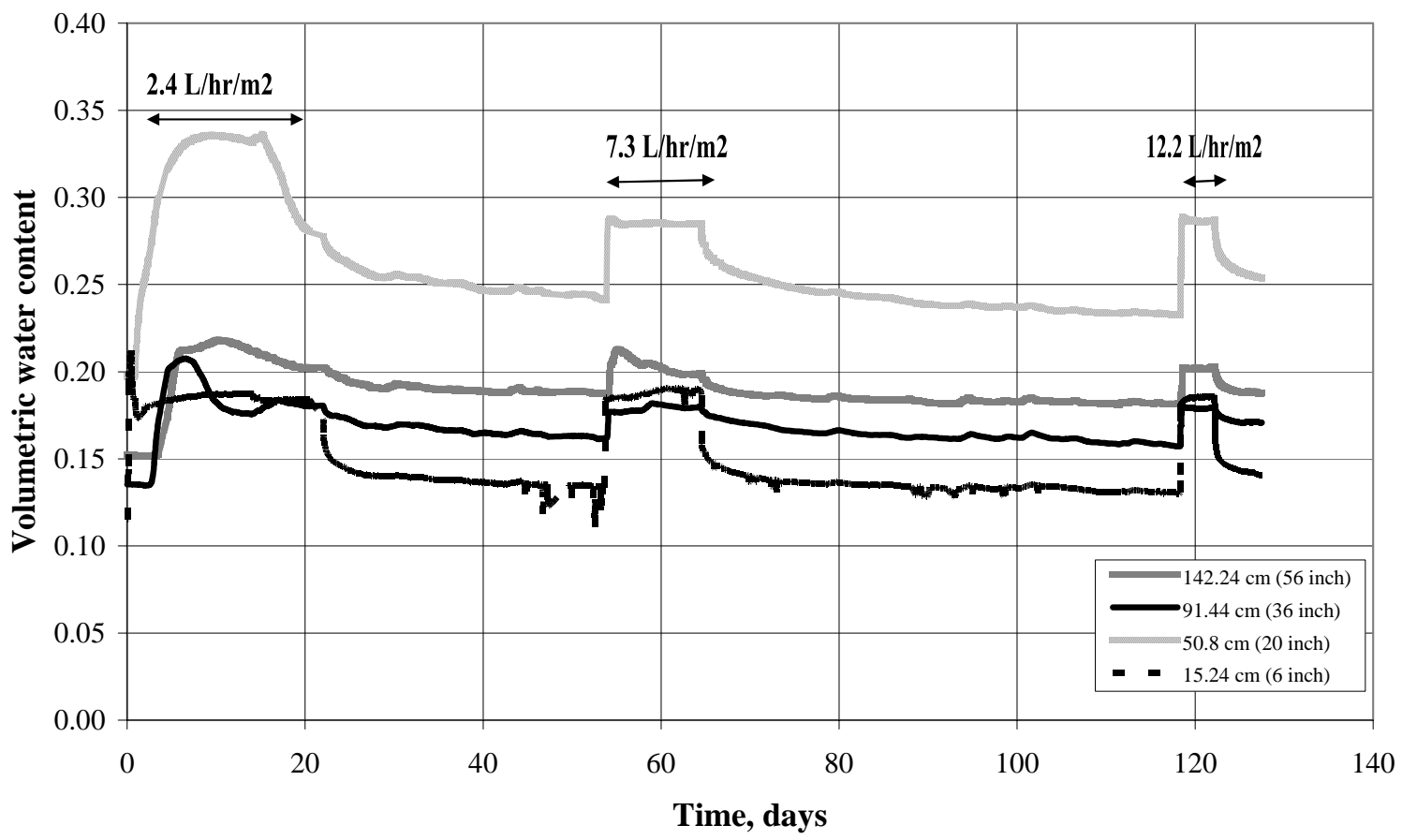

Figure 7 Volumetric water content observed with EC-20 probes in Cortez column 


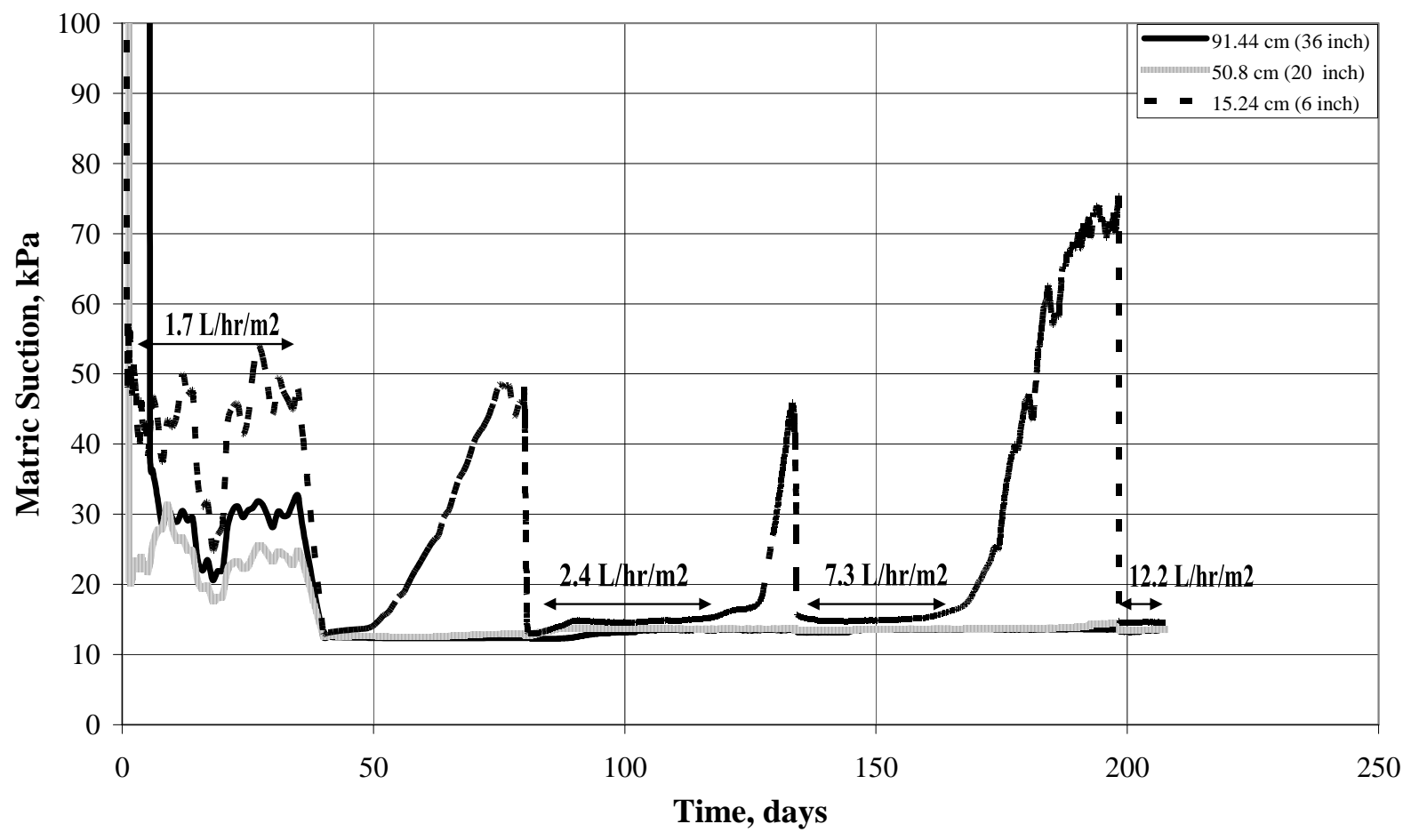

Figure 8 Matric suction observed with Echo matric probes in Rawhide column

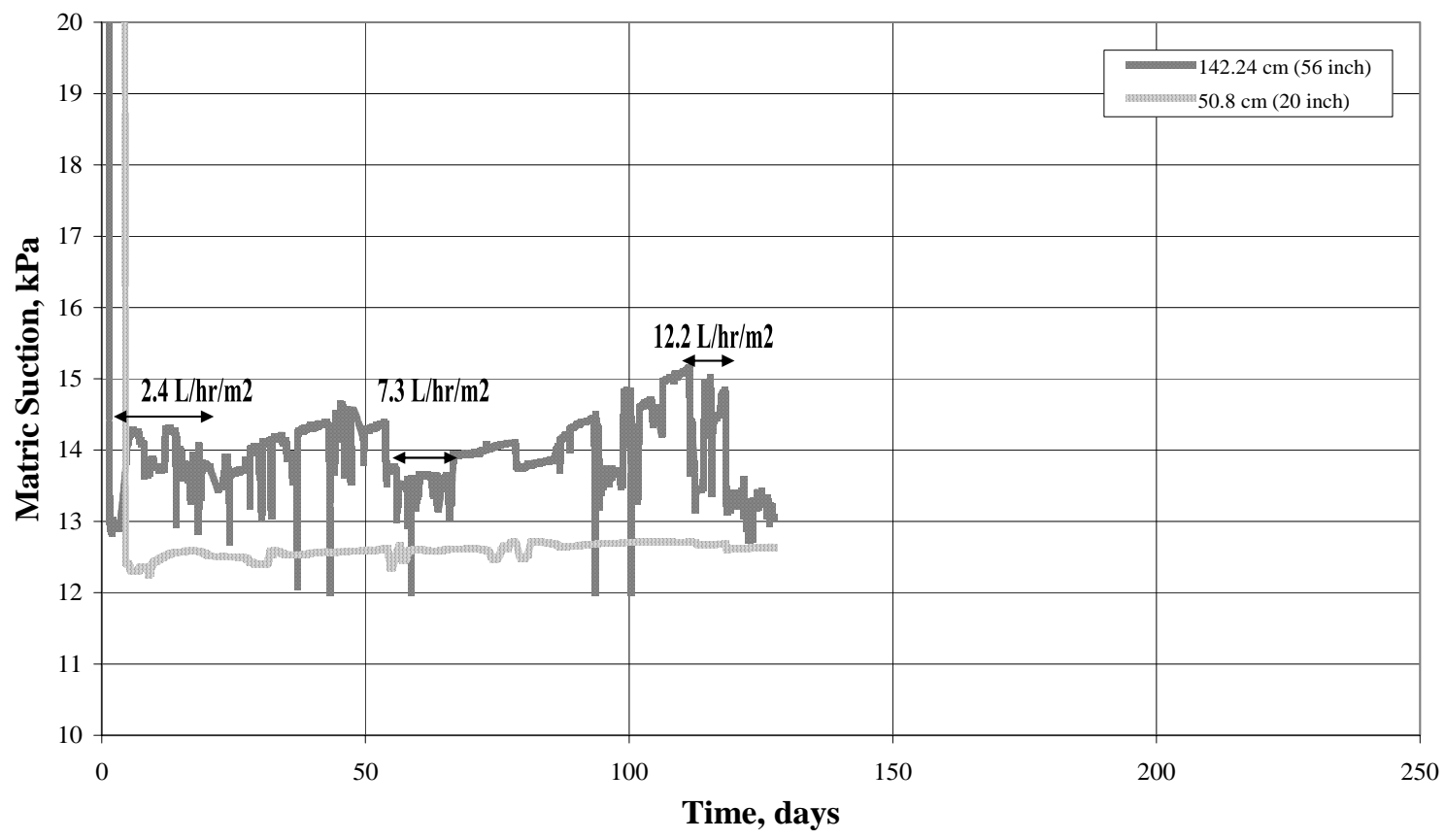

Figure 9 Matric suction observed with Echo matric probes in Cortez column 
Figure 10 shows the discharge recorded in the Rawhide column using the tipping bucket rain gauge. The discharge collected for the initial flux application rate $\left(1.7 \mathrm{~L} / \mathrm{hr} / \mathrm{m}^{2}\right)$ reached close to $1.42 \mathrm{~L} / \mathrm{hr} / \mathrm{m}^{2}$ and became steady. After 30 days the discharge recorded was $1.66 \mathrm{~L} / \mathrm{hr} / \mathrm{m}^{2}$. The application was stopped when the flow collected became steady at $1.42 \mathrm{~L} / \mathrm{hr} / \mathrm{m}^{2}$. The draindown period after the initial low flux $\left(1.7 \mathrm{~L} / \mathrm{hr} / \mathrm{m}^{2}\right)$ was 47 days when the outflow at the bottom reached zero. The next flux rate $\left(2.4 \mathrm{~L} / \mathrm{hr} / \mathrm{m}^{2}\right)$ was applied and outflow reached steady state after one day of application. The discharge collected by the rain gauge at the bottom was $2.37 \mathrm{~L} / \mathrm{hr} / \mathrm{m}^{2}$ and remained at that rate. The flux rate of $2.4 \mathrm{~L} / \mathrm{hr} / \mathrm{m}^{2}$ was applied for a period of 21 days and stopped, and draindown was observed for 32 days. The flow collected after the 32-day draindown period was close to zero. A flux of $7.3 \mathrm{~L} / \mathrm{hr} / \mathrm{m}^{2}$ was then applied for a period of 10 days where the flow collected by the rain gauge was $6.6 \mathrm{~L} / \mathrm{hr} / \mathrm{m}^{2}$. This flow was stopped after 10 days of application.

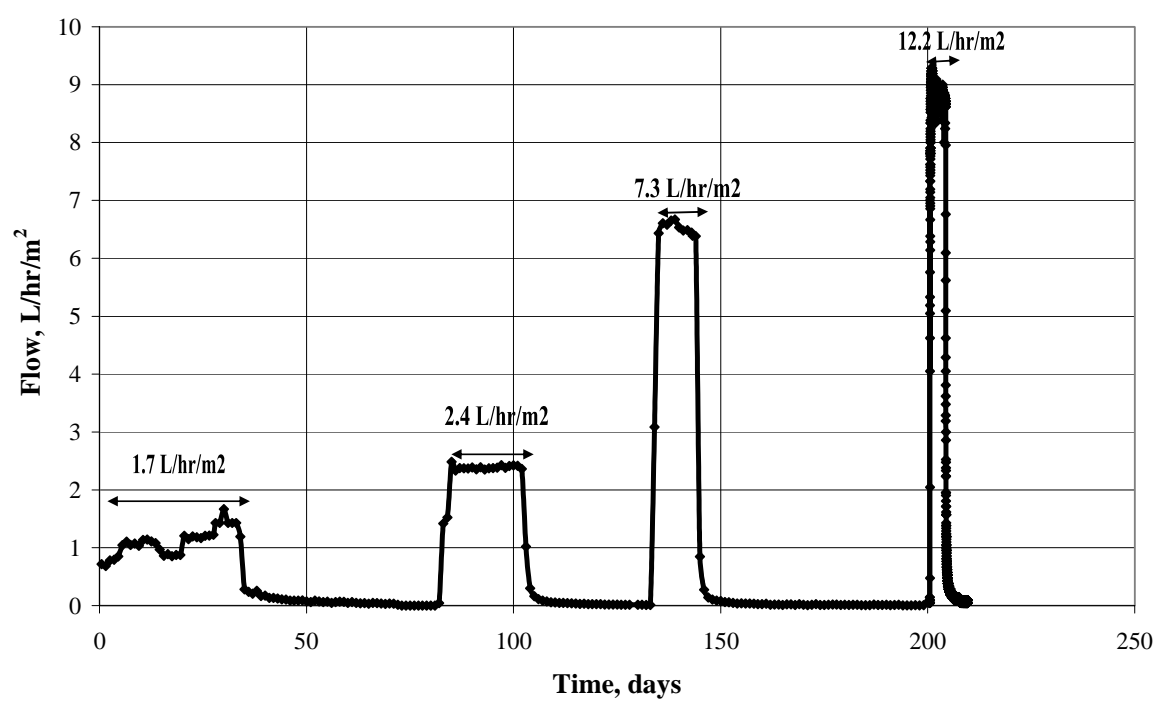

Figure 10 Measured discharge for Rawhide column at targeted flux rates

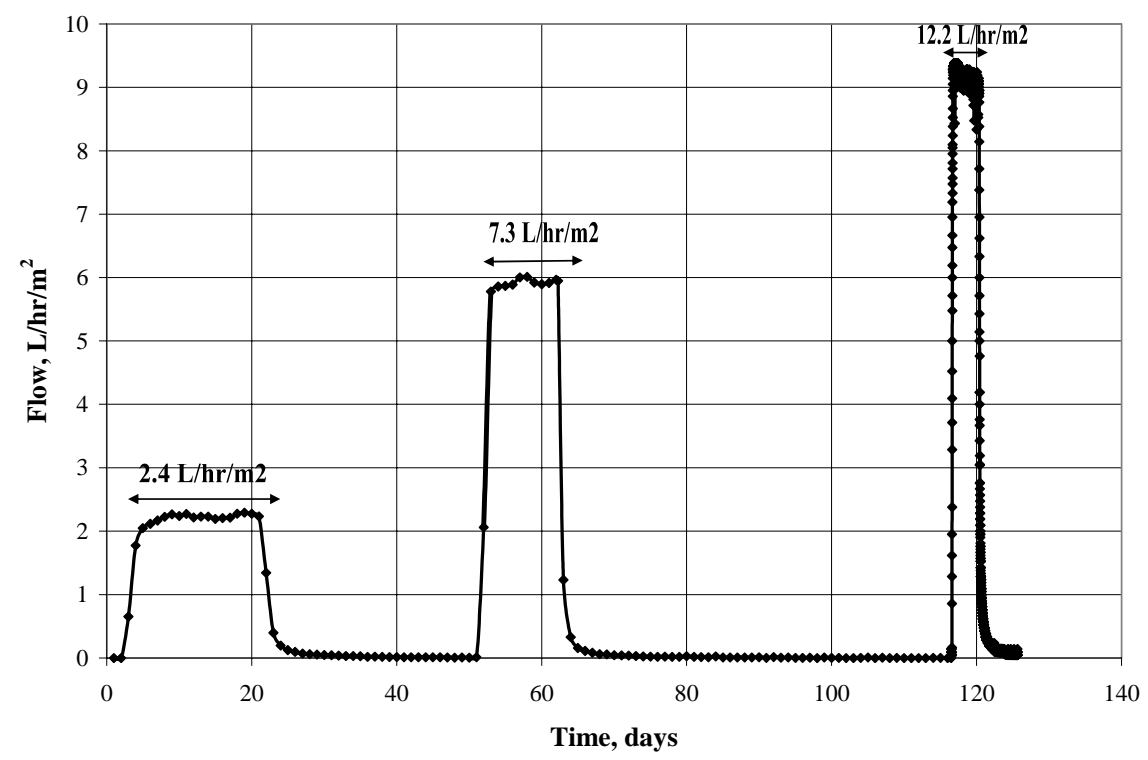

Figure 11 Measured discharge for Cortez column at targeted flux rates 
The final application rate $12.2 \mathrm{~L} / \mathrm{hr} / \mathrm{m}^{2}$ was applied after three months, which gave time to observe the draindown collection and note if there was any indication of delayed drainage from smaller pores. However, the flow collection during these three months did not show any sign of delayed drainage as the flow collected during the three-month period decreased steadily and reached zero. The final application rate of $12.2 \mathrm{~L} / \mathrm{hr} / \mathrm{m}^{2}$ was applied for 4 days after which the outflow became constant. But the flow collected at the discharge did not reach $12.2 \mathrm{~L} / \mathrm{hr} / \mathrm{m}^{2}$, instead a flow rate of $9.29 \mathrm{~L} / \mathrm{hr} / \mathrm{m}^{2}$ was obtained from the tipping bucket rain gauge.

An investigation was done to evaluate the lower than applied flows collected at the discharge for the higher applied fluxes. A detailed calibration of the rain gauge showed that the rain gauge was not responding or recording the correct discharge at higher flow rates $\left(7.3\right.$ and $\left.12.2 \mathrm{~L} / \mathrm{hr} / \mathrm{m}^{2}\right)$. The measured flow rate was $15 \%$ less for $7.3 \mathrm{~L} / \mathrm{hr} / \mathrm{m}^{2}$ and $25 \%$ less for $12.2 \mathrm{~L} / \mathrm{hr} / \mathrm{m}^{2}$ application.

While troubleshooting the recording of low discharge flow rates the manufacturer indicated that the diameter of the rain gauge was not adequate for high flow collections $\left(7.3\right.$ and $\left.12.2 \mathrm{~L} / \mathrm{hr} / \mathrm{m}^{2}\right)$. The discharge profile of the Cortez column shown in the Figure 11 displays the same characteristic low flow rates for targeted flow rates of 7.3 and $12.2 \mathrm{~L} / \mathrm{hr} / \mathrm{m}^{2}$, further confirming the problems with rain gauge measurements at higher flow rates.

\section{Discussion}

\subsection{Material characteristics}

The Cortez run-of-mine material is coarser than the crushed Rawhide material (refer to Figures 1 and 2). The maximum size particle indicated on the grain size distribution curve is not necessarily representative of the largest particles in the material because of sieve size limitations. This is especially true for the Cortez material where a small number of particles up to $150 \mathrm{~mm}$ were included in the columns.

The saturated hydraulic conductivity results of the large diameter samples determined by constant head testing show decreases with increasing gradient (refer to Table 1). This issue was not investigated further but is most likely due to turbulent flow in the coarse materials with increasing gradient. The implication maybe that Darcy's law is not valid for these materials under higher gradients.

SWCC curves for small diameter and large diameter specimens are given in Figures 3 and 4 . The material was scalped for the small diameter specimens to either minus No. 4 or minus No. 10 sieve. The following observations can be made form these results:

- The saturated water content for the coarse material is higher than for the fine material.

- The air entry value for the coarse samples is one to two orders of magnitude lower than for the fine materials.

Both these results fit the expected behaviour of the materials. The shapes of all the laboratory curves are not smooth and some indicate bimodal behaviour, this can be a material characteristic or an effect of the testing. The samples might not have reached complete equilibrium leading to the observed behaviour.

\subsection{Instrumentation}

The problems encountered with the instrument calibration were disappointing as many of the causes of these problems were not completely identified and resolved until late in the programme. In general the instruments behaved well and there is no specific reason to eliminate any of the instruments used in this programme as long as the issues are clearly understood. The following are important lessons learned:

- Purchase the data logger equipment from the manufacturer or distributor of the equipment, this means that if instruments are purchased from more than one manufacturer then multiple data loggers should also be purchased.

- Work hard to identify the person at the manufacturer/supplier of the instruments who really understands the equipment. The "front office" staff may provide contradictory information as they may not have a complete understanding of the nuances associated with the equipment. These are sophisticated equipment. 
- Make sure that long enough electrical leads are ordered for the equipment to fit the specific experimental set-up.

\subsection{Observed results}

A review of Figures 6 and 7 (volumetric water content) over time for various flux application rates provides interesting observations:

- The deepest instrument in the Rawhide column shows very little change in water content with changes in flux application. This is not the case for the Cortez column. It maybe related to the interaction between the finer Rawhide material and the drain material in the conical part of the column.

- The overall water content in the Rawhide column reduces at all remaining levels until the higher flux application rates are approached. It may be due to various factors, one of which is the potential of preferential flow developing under the higher flow rates. In this case the water may be collecting around the instruments during low flow and may flow rapidly around the instruments during higher flow allowing the local drying of the material. The Rawhide material was very dry when placed and the changes in water content during the first two flux application rates may be indicative of the time it took to reach equilibrium water contents.

- There is not a clear relationship between instrumentation depth and the observed water contents in both columns, i.e. the water content does not increase with depth in the column. This can be due to calibration issues with the equipment or it can be a real phenomenon in the columns.

- The relative behaviour of the water contents with flux application and draindown are realistic, i.e. a rapid increase in water content when the flux is applied and an exponential decay when the flux application stops.

The matric suction behaviour for the Rawhide material (Figure 8) is realistic. Matric suction increases for the uppermost instrument as it is closer to the surface where more drying takes place. The matric suction results seem to indicate that equilibrium conditions are achieved after the first flux application. The two instruments in the Cortez columns are both deeper and therefore show little increase when the flux is stopped. The relative change in the deeper instrument is still very small over the total record (about $2 \mathrm{kPa}$ ). All the matric suction values should be considered relative and not absolute.

The discharge behaviours are realistic (Figures 10 and 11). A rapid increase in flow is observed when a flux is applied and the reduction is exponential when the flux application stops.

Conducting large scale column tests require significant resources, both in terms of financial and time commitments. A certain amount of institutional knowledge is created in performing these tests and continuity in personnel availability is an important consideration if multiple tests are to be performed.

\section{Conclusions}

The results of this study show that large column tests can provide useful insights in the behaviour of unsaturated flow in coarse materials. The instruments provide a view of changes in water content and matric suction in a representative volume of material and not what happens in the individual pore. The relative behaviour of the water content and flow rate decay curves, when flux application stops, provides useful insights in the longer term behaviour following heap closure.

The experience gained in investigating unsaturated flow in large columns provides insights in the unsaturated flow behaviour of heap leach materials as well as the use of instruments in heap leach facilities. The following are some of the lessons that can be applied to heap leach operations:

- Unsaturated flow in coarse materials is complex and much is left to be learned about the characterisation of materials and the detailed flow conditions.

- Preferential flow is a reality in heap leach facilities and maybe a bigger concern at higher flux application rates. 
- The draindown behaviour for both water content and flow rate is exponential in crushed and run-of-mine materials and seems to follow the same general pattern under different flux rates. The implication is that much can be learned from the detailed monitoring of draindown during operations that can be applied at the time of closure.

- The use of instrumentation in heap leach facilities to monitor changes in water content and matric suction must be carefully considered as the results may not provide absolute values for these parameters and may result in a false sense of what "reality" is in the heaps. Heterogeneity of materials surrounding the instruments as well as potential preferential flows can result in the measurement of variable water content and matric suction. Instrumentation can provide useful trends and it is not realistic to expect more than that. They are definitely not suitable to provide absolute values for regulatory enforcement.

- The data acquisition procedure must be matched to the number of instruments being monitored. For clarity in data recording more than one data logger is required if the instruments used are from different manufacturers.

\section{Acknowledgements}

This research was funded by Cortez Gold Mines, Denton Rawhide Mining and the Nevada Applied Research Initiative. This financial support is greatly appreciated.

\section{References}

Cathles, L.M. and Murr, L.E. (1980) Evaluation of an experiment involving large column leaching of low grade copper sulphide waste: a critical test of a model of the waste leaching process, in W. J. Schlitt (ed.) Leaching and recovering copper from as-mined materials, SME of AIME, New York, pp. 29-48.

Dixon, D.G. (1992) Predicting the kinetics of heap leaching with unsteady state models. PhD Thesis, University of Nevada, Reno.

Dixon, D.G. and Hendrix, J.L. (1993) A mathematical model for heap leaching of one or more solid reactants from porous ore pellets. Metallurgical Transactions, 24B, pp. 1087-1102.

Decker, D.L. (1996) The determination of the hydraulic flow and solute transport parameters for several heap leach materials. MSc Thesis, University of Nevada, Reno.

Decker, D.L. and Tyler, S.W. (1999) Evaluation of flow and solute transport parameters for heap leach recovery materials. Journal of Environmental Quality. Vol. 28, pp. 543-555.

Dix, R.B., Comba, P.G. and McGill, S.L. (1992) Laboratory rinsing behaviours of spent ores. Proceedings 2nd Int. Conf. on environmental issues and management of waste in energy and mineral production, A.A.Balkema, Rotterdam, Netherlands, pp. 917-924.

Fredlund, D.G. and Rahardjo, H. (1993) Soil Mechanics for Unsaturated Soils. John Wiley \& Sons, Inc.

Galla, V. (2007) Investigating unsaturated flow for heap leach materials in large diameter columns, MSc Thesis, University of Nevada, Reno.

Kampf, S., Salazar, M. and Tyler, S.W. (2002) Preliminary investigation of effluent drainage from mine heap leach facilities. Vadose Zone Journal Vol. 1, pp. 186-196.

Murr, L.E., Schlitt, W.J. and Cathles, L.M. (1981) Experimental observations of solution flow in the leaching of copperbearing waste, In W.J. Schlitt (ed.) Interfacing technologies in solution mining, SME of AIME, New York, pp. 271-290.

Newman, L., Barbour, S.L., Fredlund, D.G. and Wilson, G.W. (1998) Preferential flow in vertically layered, unsaturated systems. Proceedings of the Second International Conference on Unsaturated Soils: 27-30 August, Beijing, China: UNSAT '98, pp. 586-589.

Nichol, C., Smith, L. and Beckie, R. (2000) Hydrogeologic behaviour of unsaturated mine waste rock: An experimental study. Proceedings 5th ICARD, Denver, CO., 21-24 May, pp. 215-224.

Orr, S. (2002) Enhanced heap leaching - Part 1: Insights, Mining Engineering, Vol. 54, No. 9, September, pp. 49-55.

Parker, J.C. and van Genuchten, M.Th. (1984) Determining Transport Parameters from Laboratory and Field Tracer Experiments. Bull. 84-3, Virginia Agric. Exp. Sta., Blacksburg, VA, 91 p.

van Zyl, D., Hutchison, I. and Kiel, J. (eds.) (1988) Introduction to evaluation, design and operation of precious metal heap leaching projects. Society of Exploration, Metallurgy and Mining, Littleton, CO, 372 p.

Webb, G.G.W. (2003) Spatial variability of flow in coarse, unsaturated mining material: results from field-scale infiltration experiments. MSc Thesis University of Nevada, Reno. 
Webb, G., Tyler, S.W., Collord, J., van Zyl, D., Halihan, T., Turrentine, J. and Fenstemaker, T. (2008) Field scale analysis of flow mechanisms in highly heterogeneous mining media, Vadose Zone Journal (accepted for publication). 